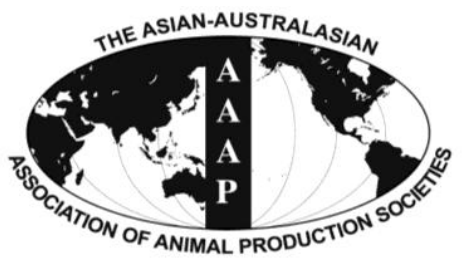

Asian Australas. J. Anim. Sci.

Vol. 26, No. 7 : 995-1002 July 2013

http://dx.doi.org/10.5713/ajas.2013.13071

www.ajas.info

pISSN 1011-2367 elSSN 1976-5517

\title{
Effect of Conjugated Linoleic Acid Feeding on the Growth Performance and Meat Fatty Acid Profiles in Broiler: Meta-analysis
}

\author{
Sangbuem Cho ${ }^{\text {a }}$, Chaehwa Ryu ${ }^{\text {a }}$, Jinho Yang, David Tinotenda Mbiriri, Chang-Weon Choi ${ }^{1}$, \\ Jung-Il Chae ${ }^{2}$, Young-Hoon Kim, Kwan-Seob Shim ${ }^{3}$, Young Jun Kim ${ }^{4}$, and Nag-Jin Choi* \\ Department of Animal Science, Chonbuk National University, Jeonju, 561-756, Korea
}

\begin{abstract}
The effect of conjugated linoleic acid (CLA) feeding on growth performance and fatty acid profiles in thigh meat of broiler chicken was investigated using meta-analysis with a total of 9 studies. Overall effects were calculated by standardized mean differences between treatment (CLA fed) and control using Hedges's adjusted g from fixed and random effect models. Meta-regression was conducted to evaluate the effect of CLA levels. Subgroups in the same study were designated according to used levels of CLA, CP levels or substituted oils in diets. The effects on final body weight, weight gain, feed intake and feed conversion ratio were investigated as growth parameters. Total saturated and unsaturated fatty acid concentrations and C16:0, C18:0, C18:2 and C18:3 concentrations in thigh meat of broiler chicken were used as fatty acid profile parameters. The overall effect of CLA feeding on final weight was negative and it was only significant in fixed effect model $(\mathrm{p}<0.01)$. Significantly lower weight gain, feed intake and higher feed conversion ratio compared to control were found $(\mathrm{p}<0.05)$. CLA feeding on the overall increased total saturated fatty acid concentration in broilers compared to the control diet $(\mathrm{p}<0.01)$. Total unsaturated fatty acid concentration was significantly decreased by CLA feeding ( $<<0.01)$. As for individual fatty acid profiles, C16:0, C18:0 and C18:3 were increased and C18:2 was significantly decreased by CLA feeding $(\mathrm{p}<0.01)$. In conclusion, CLA was proved not to be beneficial for improving growth performance, whereas it might be supposed that CLA is effective modulating n-6/n-3 fatty acids ratio in thigh meat. However, the economical compensation of the loss from suppressed growth performance and increased saturated fatty acids with the benefit from enhanced $n-6 / n-3$ ratio should be investigated in further studies in order to propose an appropriate use of dietary CLA in the broiler industry. (Key Words: Broiler Chicken, Conjugated Linoleic Acid, Growth Performance, Meat Fatty Acids, Meta-analysis)
\end{abstract}

\section{INTRODUCTION}

Oils derived from plant sources are rich in unsaturated fatty acids (UFAs) and they have been reported to show better utilization rate, lower fecal energy loss and consequently higher metabolizable energy than saturated fatty acids (SFAs) from animal sources in poultry (Crespo and Esteve-Garcia, 2001). Sunflower, safflower, corn and

\footnotetext{
* Corresponding Author: Nag-Jin Choi. Tel: +82-63-270-2579,

Fax: +82-63-270-2612, E-mail: nagjin@jbnu.ac.kr

${ }^{1}$ Department of Animal Resource, Daegu University, Kyongsan, 712-714, Korea.

2 Department of Dental Pharmacology, Chonbuk National University, Jeonju, 561-756, Korea.

3 Department of Animal Biotechnology, Chonbuk National University, Jeonju, 561-756, Korea.

${ }^{4}$ Department of Food and Biotechnology, Korea University, Chochiwon, 339-700, Korea.

a These authors contributed equally to this work.

Submitted Jan. 29, 2013; Accepted Mar. 12, 2013; Revised Apr. 28, 2013
}

soybean oils are commonly used practical feeds to supply oils in poultry diet. These ingredients contain high amounts of n-6 FAs (Schreiner et al., 2005; Cleland et al., 2006) and that brings about a higher accumulation of $\mathrm{n}-6$ FAs in meats, even though poultry meat has been generally considered as a main source of polyunsaturated FA (PUFA), particularly n-3 FAs (Ponte et al., 2008). Increasing consumption of food containing high $n-6 / n-3$ FAs ratio is recognized to be associated with a higher incidence of health problems in humans (Simopoulos, 1999; Shin et al., 2011). So, the recent feeding strategy in poultry has moved to increasing n-3 FAs accumulation in meat by adding n-3 FAs in diets as a substitution for $\mathrm{n}-6$ FAs rich ingredients. However, offflavors and particularly susceptibility to oxidative deterioration during storage in meat were reported to be related to increasing levels of n-3 FAs in poultry diets (Ponte et al., 2008; Shin et al., 2011; Lee et al., 2012). For a strategy to increase n-3 FAs content and reduce n-6/n-3 FAs ratio in meat, incorporation of conjugated linoleic acid 
(CLA) in diets has been suggested (Du and Ahn, 2003; Shin et al., 2011). This concurs with earlier findings that CLA in diets may induce changes animal FAs composition by its action on the activity of enzymes involved in desaturation of FAs (Hur et al., 2007). However, it is not easy to decipher the concurring results of the effect of CLA feeding on FAs composition in meat from feeding trials, particularly about its effect on growth performance. It was also proposed that the effect of CLA on lipid metabolism in broilers is different from other animals, such as rat, mice and pig (Du and Ahn, 2003). The present study was conducted to draw a conclusion on the effect of CLA feeding on growth performance and FAs profiles of meat of broilers. Meta-analysis was employed with 9 studies that reported the result of feeding trials.

\section{MATERIALS AND METHODS}

\section{Data sets}

Nine studies (24 experiments) that reported the effect of CLA feeding on growth performance and/or FAs profiles in meat of broiler chickens were identified by a computerized literature search. Research articles were selected based on use of CLA, presence of a control group without CLA supplementation and presence of a measurement of standard deviation or error.

\section{Data analysis}

The mean difference between control and treatment groups using Hedges's adjusted g for pooling was used for calculation of a standardized mean difference (SMD). Estimated effect sizes from used studies were visualized in forest plot. Summary effects across the studies were calculated using fixed and random effects models. The inverse weighting for pooling and the DerSimonian-Laird estimate for between-study variance were used in random effect model. When calculating the overall effect, the study showing a weight in random effect model below 5\% was regarded as out-layer and not applied to analysis. A heterogeneity test to investigate common effect sizes and its dispersion among used studies was performed. Cochran's Q test and the ratio of true heterogeneity to total variation in observed effects was represented by $\mathrm{I}^{2}$ index in forest plot. Effect of CLA levels in diet was measured by metaregression using the mixed-effect model. Statistical analysis and visualization of standardized mean differences were performed using the package 'meta' in the $\mathrm{R}$ statistical program (version 2.14.2) ( $\mathrm{R}$ Development Core Team, 2010).

\section{RESULTS}

\section{Data set}

A total of 9 published research studies reporting the feeding trials of broiler chicken using dietary CLA were used as the data set and their experimental conditions were summarized in Table 1. The broiler breeds used were Cobb $\times$ Ross in one study, Arbor Acre in two studies and Ross breed in the remaining studies. CLA was incorporated into feed in different levels ranging from $0.25 \%$ to $5 \%$ and it was substituted with various oil sources in diet, completely or partially: soybean oil (2 studies), sunflower oil ( 2 studies), corn oil (2 studies), olive oil (1 study), beef tallow (1 study), hazelnut oil (1 study), flaxseed oil (1 study) and menhaden oil (1 study). Two studies did not mention substitution oils. Experimental days were varied from 21 to $42 \mathrm{~d}$ across studies. CLA was fed from d 1 of chick to the day of slaughter in 4 studies and the remaining studies started CLA feeding from mid to end of experiment resulting in an average duration of feeding of about $16.8 \mathrm{~d}$. Major isomers in used CLA were c-9, t-11/c-12, t-10. Metabolizable energy in the diets ranged from 2,998 to $3,344 \mathrm{kcal} / \mathrm{kg}$ and crude protein was from 19.35 to $23.00 \%$. The study of Badinga et al. (2003) was used for investigation of final body weight (FBW), and weight gain (WG). However, it was recognized as an outlier in both analyses because of low weight in the random effect model.

\section{Effect of conjugated linoleic acid feeding on growth performance}

The overall effect of CLA feeding on final weight was calculated using 16 experiments in 6 studies (Table 2). Subgroups in the same study were designated according to used levels of CLA in diets or different CP levels in basal diet or different oils substituted by CLA. These different experiments in the same study were expressed as subgroups. For the calculation of the overall effect on WG, 16 subgroups in 7 studies were employed. Body weight gain (BWG) was measured by the difference of body weight between initial weight and FBW except for one study (Zhang et al., 2008) where average daily gain was applied. Feed intake (FI) was estimated from total consumed feed weight during experimental periods and 12 subgroups in 5 studies were used in calculation of the overall effect. The overall effect of CLA feeding on feed conversion ratio (FCR) was estimated by using 11 subgroups in 4 studies. The overall effect of CLA feeding on growth performance of broiler chicken is shown in Table 2. CLA feeding effect on FBW of broiler chicken was detected as negative in both fixed and random effects models. A significant negative effect means that the FBW at the treatment group (broiler fed CLA) was lower than the control group. A significant effect of treatment on FBW was found only in the fixed effect model $(p<0.001)$. During the calculation of the overall effect, one study was rejected for its weight which was below 5\% in the random effect model. In heterogeneity, the $\mathrm{Q}$ statistic was 361.61 and was significant $(\mathrm{p}<0.01)$ for 
Table 1. Studies used in data sets and their information for feeding trials

\begin{tabular}{|c|c|c|c|c|c|c|}
\hline \multirow[b]{2}{*}{ Study } & \multirow[b]{2}{*}{ Animal $^{1}$} & \multirow[b]{2}{*}{$\mathrm{DOE}^{2}$} & \multicolumn{3}{|c|}{ Conjugated linoleic acids } & \multirow{2}{*}{$\begin{array}{l}\text { Feeding } \\
\text { practices }\end{array}$} \\
\hline & & & Levels (\%) & $\begin{array}{l}\text { Substituted } \\
\text { oils }^{3}\end{array}$ & Isomers profiles ${ }^{4}$ & \\
\hline Kim et al. (2008) & A & $5 \times 4 \times 10$ & $0.5,1.0,1.5,2.0$ & No info. & $\begin{array}{l}\text { (A), c-9, t-11 }(24.1 \%) ; \mathrm{t}-10, \mathrm{c}-12 \\
(25.6 \%) ; \text { others }\end{array}$ & $\begin{array}{l}\text { Basal: } 1-7 \mathrm{~d} \\
\text { CLA: } 8-35 \mathrm{~d}\end{array}$ \\
\hline Aletor et al. (2003) & $\mathrm{R}$ & $6 \times 6 \times 9$ & 4.0 & $\begin{array}{l}\text { Soybean oil } \\
\text { (partially) }\end{array}$ & $\begin{array}{l}\text { (B), C18:1 (14.2\%); C18:2 (n-6) } \\
(4.0 \%) ; \mathrm{c}-9, \mathrm{t}-11(34.2 \%) ; \mathrm{t}-10, \mathrm{c}- \\
12(34.0 \%) ; \text { other CLA }(4.0 \%) ; \\
\mathrm{C} 18: 3(0.02 \%) ; \text { other fatty acid } \\
(9.6 \%)\end{array}$ & $\begin{array}{l}\text { Basal: } 1-21 \mathrm{~d} \\
\text { CLA: } 22-42 \mathrm{~d}\end{array}$ \\
\hline Zhang et al. (2008) & A & $4 \times 6 \times 10$ & $0.25,0.5,1.0$ & Soybean oil & $\begin{array}{l}\text { (C), c-9, t-11 (39.2\%); t10, c12 } \\
(38.9 \%) \text {, other CLA }(2.0 \%)\end{array}$ & CLA: $1-42 \mathrm{~d}$ \\
\hline Javadi et al. (2007) & $\mathrm{R}$ & $2 \times 8 \times 4$ & 1.0 & Sunflower oil & $\begin{array}{l}\text { (D), CLA- } 79.5 \% \text {; c-9, t-11, t-10, c- } \\
12 \text { all in equal amount }\end{array}$ & $\begin{array}{l}\text { Basal: } 1-21 \mathrm{~d} \\
\text { CLA: } 22-28 \mathrm{~d}\end{array}$ \\
\hline Ko et al. (2005) & $\mathrm{R}$ & $3 \times 2 \times 8$ & $0.75,1.5$ & Corn oil & $\begin{array}{l}\text { (A), c-9,t-11 (24.1\%), t-10, c-12 } \\
(25.6 \%) \text {; others }\end{array}$ & $\begin{array}{l}\text { Basal: } 1-21 \mathrm{~d} \\
\text { CLA: } 22-35 \mathrm{~d}\end{array}$ \\
\hline Takahashi et al. (2002) & $\mathrm{R}$ & $2 \times 8 \times 2$ & 1.0 & No info. & $\begin{array}{l}(\mathrm{E}), \mathrm{c}-9, \mathrm{t}-11 / \mathrm{t}-9, \mathrm{c}-11(34.5 \%) ; \mathrm{t}- \\
10, \mathrm{c}-12(35.7 \%) ; \mathrm{c}-9, \mathrm{c}-12 / \mathrm{c}-10, \mathrm{c}- \\
12, \mathrm{t}-9, \mathrm{t}-11 / \mathrm{t}-10, \mathrm{t}-12(2.4 \%)\end{array}$ & $\begin{array}{l}\text { Basal: } 1-10 \mathrm{~d} \\
\text { CLA: } 11-24 \mathrm{~d}\end{array}$ \\
\hline Aydin (2007) & $\mathrm{R}$ & $5 \times 2 \times 35$ & 0.5 & $\begin{array}{l}\text { Sunflower, olive, } \\
\text { beef tallow, } \\
\text { hazelnut oils } \\
\text { (individually) }\end{array}$ & $\begin{array}{l}(\mathrm{N}), \mathrm{c}-9, \mathrm{t}-11, \mathrm{t}-9, \mathrm{c}-11(35.33 \%) ; \mathrm{t}- \\
10, \quad \mathrm{c}-12 \quad(35.72 \%) ; \quad \mathrm{c}-9, \quad \mathrm{c}-11 \\
(1.11 \%) ; \mathrm{c}-10, \mathrm{c}-12(1.57 \%) ; \mathrm{t}-9, \mathrm{t}- \\
11, \mathrm{t}-10, \mathrm{t}-12(0.91 \%)\end{array}$ & CLA: $1-35 \mathrm{~d}$ \\
\hline Badinga et al. (2003) & $\mathrm{R}$ & $2 \times 12 \times 4$ & 5.0 & Corn oil & $\begin{array}{l}(\mathrm{F}), \quad \mathrm{c}-9, \mathrm{t}-11 \quad(30.7 \%) ; \mathrm{t}-10, \mathrm{c}-12 \\
(30.6 \%) ; \mathrm{t}-9, \mathrm{t}-11(2.3 \%)\end{array}$ & CLA: $1-21 \mathrm{~d}$ \\
\hline Shin et al. (2011) & $\mathrm{CR}$ & $5 \times 4 \times 6$ & 2.0 & $\begin{array}{l}\text { Flaxseed and } \\
\text { menhaden oils }\end{array}$ & $\begin{array}{l}(\mathrm{G}), \mathrm{c}-9, \mathrm{c}-11 \quad(50 \%) ; \mathrm{t}-10, \mathrm{c}-12 \\
(50 \%)\end{array}$ & CLA: $1-42 \mathrm{~d}$ \\
\hline
\end{tabular}

${ }^{1}$ Animal = A, Arbor Acre; R = Ross; CR = Cobb $\times$ Ross.

${ }^{2} \mathrm{DOE}=$ Design of experiment, no. of treatment $\times$ no. of replication $\times$ animals per replication.

${ }^{3}$ Substituted oil sources in feed with CLA.

${ }^{4}$ CLA manufacturers: (A), Chumdan Yangdon Institute, Korea; (B), TrofoCell Research and Trade GmbH, Hamburg, Germany; (C), Auhai Biotech Ltd, Qingdo, P. R. China; (D), Lipid Nutrition B.V. Wormerveer, The Netherland; (E), Rinoru Oil Milss Co. Ltd Tokyo Japan; (F), BASF, D-67056 Ludwigshafen, Germany; (G), Luta-CLA 60, BASF, Ludwigshafen, Germany, (N), no information.

FBW. With high and significant heterogeneity results, it could be suggested that the used studies or subgroups did not share a common effect size. Individual SMDs in subgroups and studies are shown in Figure 1A. The positive minimum value of $95 \%$ critical interval was found in four subgroups in the study of Aydin (2007), where CLA feeding was compared with flaxseed, menhaden oil and combination. The overall effect on WG was negative in both fixed and random models $(\mathrm{p}<0.01)$. The $\mathrm{Q}$ statistic and its probability on WG were 204.53 and $p<0.01$ respectively. Individual SMDs in all subgroups except studies no. wg9 to wg11 involved in the study from Zhang et al. (2008) showed negative effects (Figure 1B). Interestingly, where the study showed positive effects, CLA was fed from day one to slaughter. As for FI, a significantly negative overall effect of dietary CLA was detected in both fixed and random models $(\mathrm{p}<0.05)$. The $\mathrm{Q}$ statistic and its probability on FI were 100.27 and significant $(\mathrm{p}<0.01)$, respectively. The largely dispersed $95 \%$ confidence interval (CI) for each SMD over positive and negative from investigated studies were detected as shown in Figure 1C. The overall effect on FCR was significantly positive in both fixed and random models $(p<0.05)$. The pattern of individual SMDs for FI (Figure 1C) show a converse pattern to that exhibited in

Table 2. Effect of CLA feeding on the growth performance of broiler chicken

\begin{tabular}{|c|c|c|c|c|c|c|c|c|c|}
\hline \multirow{2}{*}{ Items $^{1}$} & \multirow{2}{*}{$\mathrm{df}^{2}$} & \multicolumn{3}{|c|}{ Fixed effect model $^{3}$} & \multicolumn{4}{|c|}{ Random effect model } & \multirow{2}{*}{$\begin{array}{c}\text { Heterogeneity } \\
\mathrm{Q}^{5}(\mathrm{p} \text {-value })\end{array}$} \\
\hline & & ES & z-value & $\mathrm{p}$-value & ES & z-value & p-value & $\mathrm{N}<5 \%{ }^{4}$ & \\
\hline$\overline{\mathrm{FBW}}$ & 14 & -0.2998 & -4.6391 & $<0.0001$ & -0.0540 & -0.1630 & 0.8705 & 1 & $361.61(<0.0001)$ \\
\hline WG & 14 & -0.4939 & -8.2970 & $<0.0001$ & -0.6410 & -2.7788 & 0.0055 & 1 & $204.53(<0.0001)$ \\
\hline FI & 11 & -0.3760 & -5.4107 & $<0.0001$ & -0.4219 & -1.9964 & 0.0492 & 0 & $100.27(<0.0001)$ \\
\hline FCR & 10 & 0.3737 & 5.3644 & $<0.0001$ & 0.3867 & 1.9648 & 0.0494 & 0 & $77.61(<0.0001)$ \\
\hline
\end{tabular}

${ }^{1}$ FBW = Final body weight; WG = Weight gain; FI = Feed intake; FCR = Feed conversion ratio

${ }^{2} \mathrm{df}=$ degree of freedom. ${ }^{3} \mathrm{ES}=$ Overall effect size.

${ }^{4}$ Number of eliminated studies that showed a weight below $5 \%$ in the random model. ${ }^{5}$ Cochran's Q test. 


\section{A}

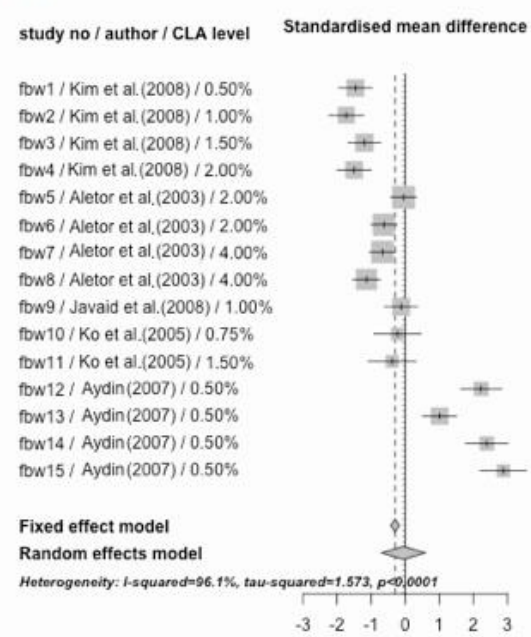

C

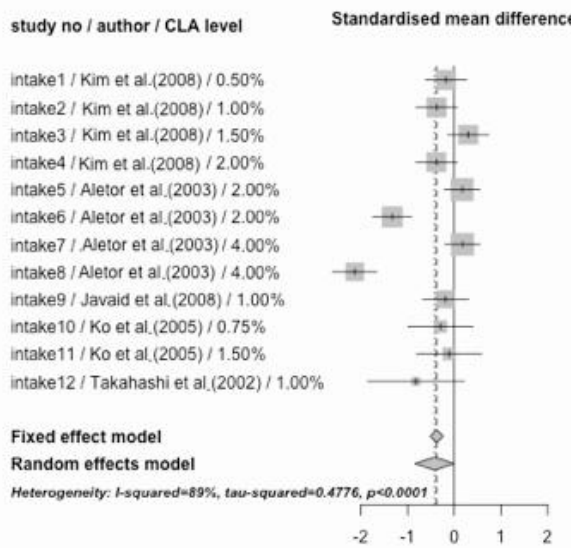

B

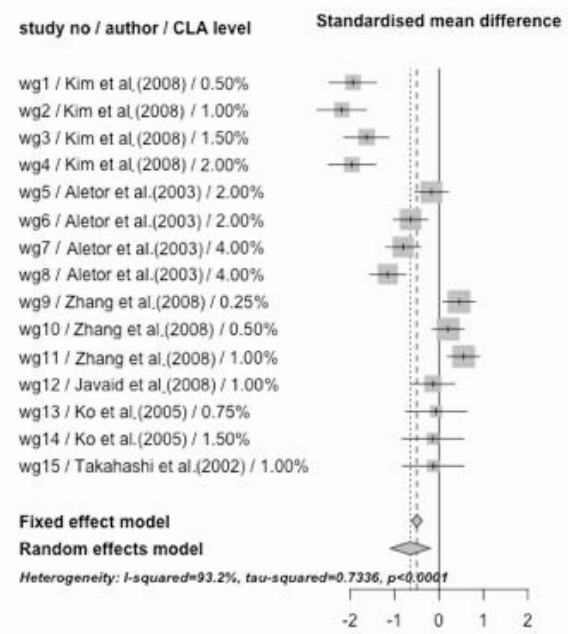

D

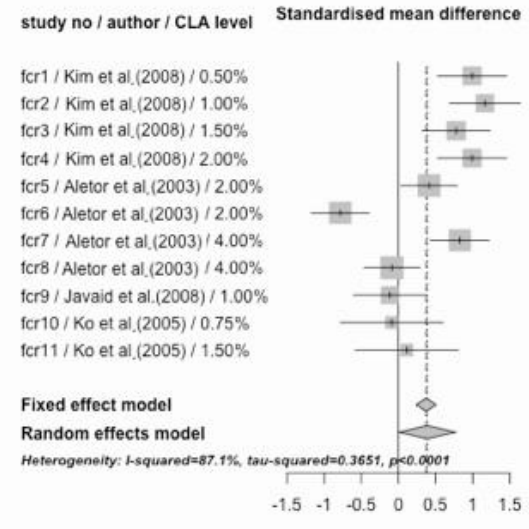

Figure 1. Forest plots for the effect of CLA feeding on growth performance of broiler.

Figures $1 \mathrm{~A}$ and $1 \mathrm{~B}$.

Effect of conjugated linoleic acid feeding on fatty acid profiles in thigh meat

The overall effects of CLA feeding on total SFA, USFA and C16:0, C18:0, C18:2 and C18:3 in thigh meat of broiler chicken are shown in Table 3 . Total SFA content in thigh meat was significantly increased by CLA feeding in both of fixed and random effect models $(\mathrm{p}<0.01)$. The $\mathrm{Q}$ statistic was 134.53 and it was significant $(\mathrm{p}<0.01)$. In the calculation of overall effects, one subgroup involved in the study of Kim et al. (2008) was not used because of its low weight (under 5\%). All subgroups applied to the analysis of total SFA were detected to represent a positive value for the

Table 3. Effect of CLA feeding on fatty acid profiles of chicken thighs

\begin{tabular}{|c|c|c|c|c|c|c|c|c|c|}
\hline \multirow{2}{*}{ Items $^{1}$} & \multirow{2}{*}{$\mathrm{df}^{2}$} & \multicolumn{3}{|c|}{ Fixed effect model ${ }^{3}$} & \multicolumn{4}{|c|}{ Random effect model } & \multirow{2}{*}{$\begin{array}{c}\text { Heterogeneity } \\
\mathrm{Q}^{5}(\mathrm{p} \text {-value })\end{array}$} \\
\hline & & ES & z-value & p-value & ES & z-value & p-value & $\mathrm{N}<5 \%{ }^{4}$ & \\
\hline TSFA & 7 & 6.0828 & 12.1000 & $<0.0001$ & 12.1213 & 4.9631 & $<0.0001$ & 1 & $134.53(<0.0001)$ \\
\hline TUSFA & 10 & -1.6014 & -7.0992 & $<0.0001$ & -2.9005 & -4.1307 & $<0.0001$ & 3 & $87.64(<0.0001)$ \\
\hline C16:0 & 8 & 5.3095 & 14.2700 & $<0.0001$ & 8.1144 & 5.0817 & $<0.0001$ & 0 & $128.92(<0.0001)$ \\
\hline C18:0 & 8 & 0.5057 & 3.3106 & 0.0009 & 1.8968 & 3.6932 & 0.0002 & 0 & $62.54(<0.0001)$ \\
\hline C18:2 & 11 & -2.0036 & -10.0130 & $<0.0001$ & -4.2733 & -4.7834 & $<0.0001$ & 0 & $193.87(<0.0001)$ \\
\hline C18:3 & 10 & 0.5076 & 3.7712 & 0.0002 & 0.3758 & 1.2857 & 0.1985 & 3 & $43.12(<0.0001)$ \\
\hline
\end{tabular}

${ }^{1}$ TSFA and TUSFA mean total saturated fatty acid and total unsaturated fatty acid, respectively.

${ }^{2} \mathrm{df}=$ Degree of freedom. ${ }^{3} \mathrm{ES}=$ Overall effect size.

${ }^{4}$ Number of eliminated study that showing below $5 \%$ of weight in random model. ${ }^{5}$ Cochran's Q test. 
A

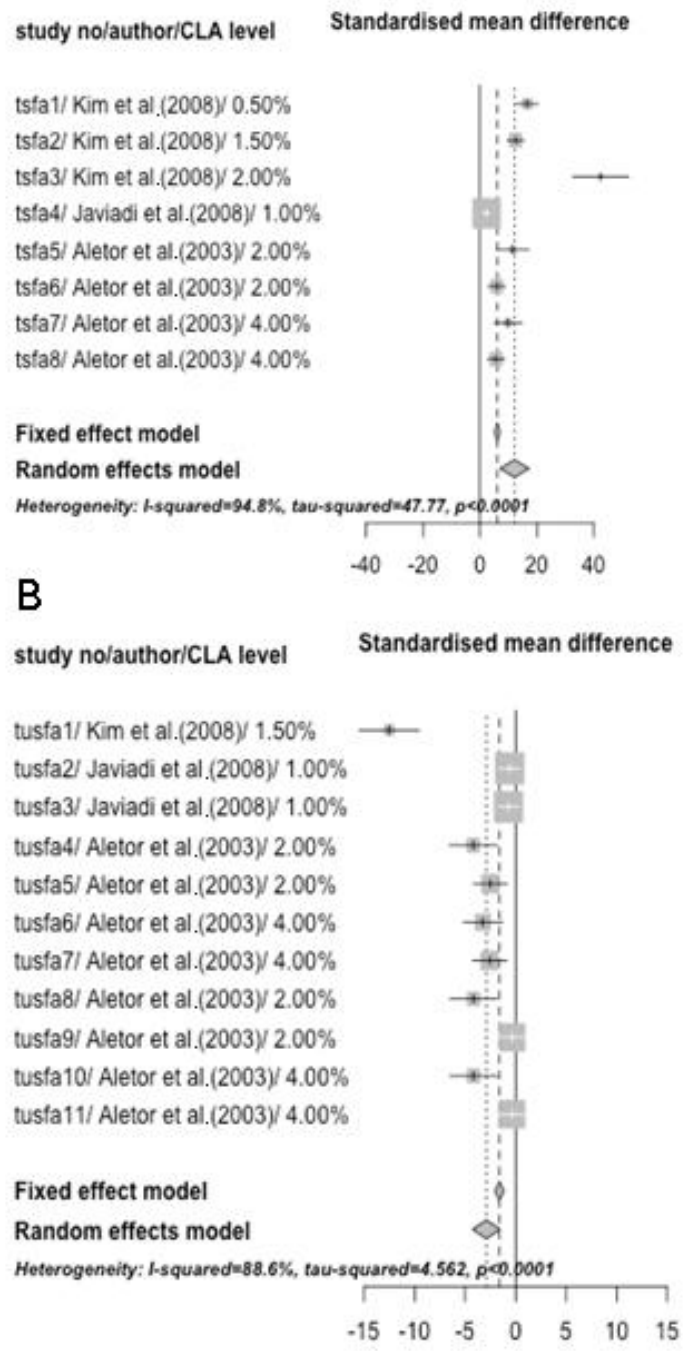

Figure 2. Forest plots for the effect of CLA feeding on total saturated fatty acid (A) and unsaturated fatty acid (B) in thigh meat of broiler chicken.

lower limit of 95\% CI in SMDs (Figure 2A). Significantly less total USFA content in thigh meat of the broiler fed CLA compared to control was found in both of fixed and random effect models $(\mathrm{p}<0.01)$. Three subgroups were declined for their low weight below 5\%. The Q statistic was 87.64 and it was significant $(p<0.01)$. Negative upper limits for the $95 \%$ confidence level were found in most subgroups except for four subgroups that showed relatively high weights (Figure 2B). Significant positive overall effects on C16:0 and C18:0 were found in both fixed and random effect models $(\mathrm{p}<0.01)$. Positive SMDs were found in all used subgroups (Figure 3A). The overall effect of CLA feeding on C18:3 was positive and the significant effect was found in only the fixed effect model $(\mathrm{p}<0.01)$. On the contrary, a significant negative overall effect was detected in $\mathrm{C} 18: 2(\mathrm{p}<0.01)$. The Q statistics for C18:3 and C18:2 were 43.12 and 193.87, respectively. Heterogeneities for the two fatty acids were significant $(\mathrm{p}<0.01)$. In forest plots representing individual SMDs, C18:3 (Figure 3C) and C18:2 (Figure 3D) showed quite different patterns from each other. The SMDs for C18:3 were highly dispersed (Figure 3C). Although there were large negative SMDs with small weight in C18:2, most SMDs with large weight were slightly negative (Figure 3D).

\section{Effect of conjugated linoleic acid levels: meta-regression}

$\mathrm{I}^{2}$ index values in all forest plots were relatively large. This suggests that there are possible effects from used subgroups. The levels of CLA in diets were used as one of the criteria in designing subgroups from studies. Therefore, a meta-regression analysis with different levels of CLA was then performed and summarized in Table 4. The coefficients for slope in all items in the growth performance category were negative, and significance was found only in the FBW $(p<0.05)$. As for fatty acid profiles, a significant effect of CLA levels in diet was found only in stearic acid $(p<0.01)$, and its effect was positive.

\section{DISCUSSION}

\section{Conjugated linoleic acid}

A lipid like substance derived from pan-fried hamburger supposed to contain anti-mutagenic function was firstly reported in 1979 (Pariza et al., 1979) and it was later identified as CLA. Since this finding, CLA has been researched in broad fields of science and reported to be positive to health. CLA is a collective term for geometric and positional isomers of linoleic acid, and all these isomers have a conjugated double bond instead of the methyleneseparation (Schmid et al., 2006). The CLA content in foods derived from ruminant animal products is markedly higher than those from mono-gastric animals (Chin et al., 1992). The reason for particularly high CLA content in the food from ruminant products is explained by the action of rumen bacteria: biohydrogenation of linoleic acid - a phenomenon for the addition of hydrogen to unsaturated fatty acid (Badinga et al., 2003). Biological functions of CLA such as the suppressing activity against cancer, obesity and arteriosclerosis are well documented in many studies and these functions are regarded to be from its action on the modification of lipid metabolism and antioxidant activity (Ko et al., 2004; Hur et al., 2007; Zhang et al., 2008). Its health benefit activity was also suggested to be through the breakdown of endotoxin and reduction of prostaglandin secretion (Takahashi et al., 2002).

\section{Conjugated linoleic acid and growth performance in broiler}

From the summary effects of CLA feeding on growth 
A

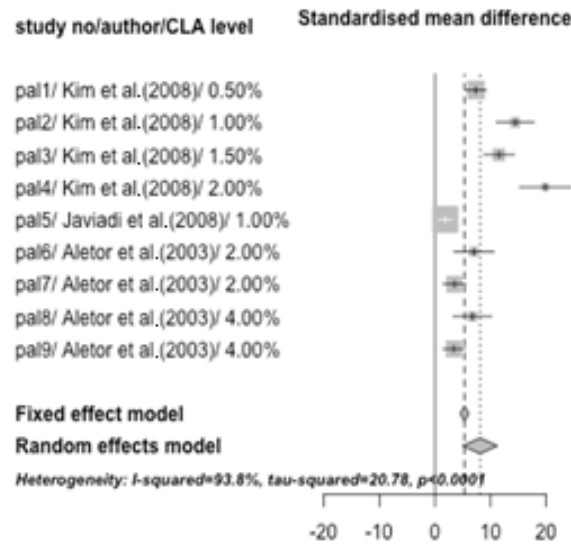

C

study no/author/CLA level Standardised mean difference

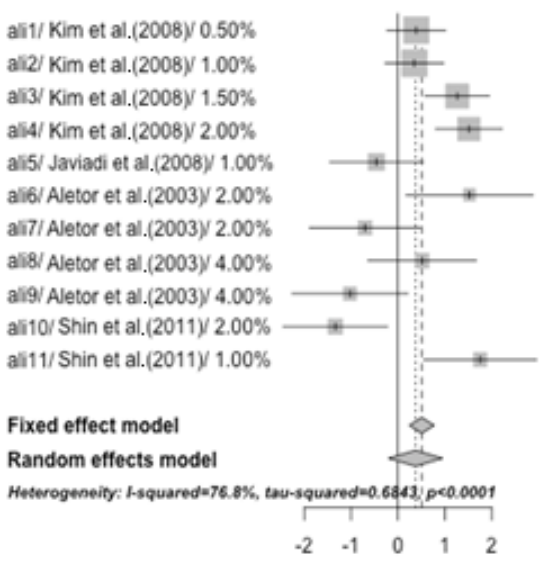

B

study no/author/CLA level

st1/ Kim et al. (2008) $0.50 \%$ ste/ Kim et al.(2008) $1.00 \%$ st3/ Kim et al.(2008) $1.50 \%$ st4/ Kim et al.(2008) $2.00 \%$ st5/ Javiadi et al.(2008)/ $1.00 \%$ st6/ Aletor et al. (2003)/2.00\% st7/ Aletor et al.(2003)/ $2.00 \%$ st8/ Aletor et al. (2003)/ $4.00 \%$ st9/ Aletor et al.(2003)/ $4.00 \%$

\section{Fixed effect model} Random effects model

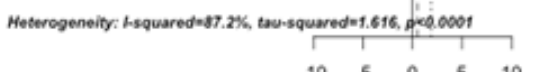

D

study no/author/CLA level

Standardised mean difference

lin $1 /$ Kim et al.(2008)/ $0.50 \%$ lin2/ Kim et al.(2008)/ $1.00 \%$ lin $3 /$ Kim et al. $(2008) / 1.50 \%$ lin $4 /$ Kim et al. (2008) $2.00 \%$ lin5/ Aletor et al.(2003) $2.00 \%$ lin6/ Aletor et al.(2003) $2.00 \%$ lin7/ Aletor et al.(2003) $4.00 \%$ lin8/ Aletor et al.(2003) $4.00 \%$ ling/ Shin et al. (2011)/ $2.00 \%$ lin10/ Shin et al.(2011) $2.00 \%$ lin11/ Shin et al.(2011) 1.00\% lin12/ Shin et al. (2011) $1.00 \%$

Fixed effect model

Random effects model

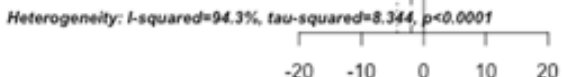

Figure 3. Forest plots for the effect of CLA feeding on fatty acid profiles in thigh meat of broiler chicken. (A) palmitic acid, (B) stearic acid, (C) C18:3, (D) C18:2.

parameters in this study, it was found that CLA is not beneficial for growth performance of broiler chicken. This is consistent with the results from Simon et al. (2000), Du and Ahn (2003) and An et al. (2003). This negative effect of CLA was suggested to be arising from its function on the acceleration of fatty acid oxidation and consequently increased metabolic rate (West et al., 1998). However, CLA was also proposed to positively affect growth performance under stressful conditions such as endotoxin or vaccination through its antioxidant and reduction of inflammation

Table 4. Effect of CLA levels in diet on growth performance and fatty acids profiles in thigh of broiler chicken

\begin{tabular}{lccc}
\hline Category & Items & Slope & Intercept \\
\hline Growth performance & FBW & $-0.5894 \pm 0.2754(0.0324)^{1}$ & $0.8271 \pm 0.5186(0.1107)$ \\
& WG & $-0.2089 \pm 0.2000(0.2969)$ & $-0.3183 \pm 0.3818(0.4044)$ \\
Fatty acids profiles & FCR & $-0.2185 \pm 0.1952(0.2632)$ & $-0.0268 \pm 0.4152(0.9485)$ \\
& Total SFA & $-0.0576 \pm 0.1813(0.7507)$ & $0.4944 \pm 0.3981(0.2143)$ \\
& Total USFA & $-1.2668 \pm 2.4261(0.6000)$ & $15.0235 \pm 5.8924(0.0108)$ \\
& C16:0 & $0.1494 \pm 0.6269(0.8116)$ & $-3.3094 \pm 1.735(0.0562)$ \\
& C18:0 & $-0.9898 \pm 1.4754(0.5023)$ & $10.1301 \pm 3.4175(0.0030)$ \\
& C18:3 & $1.4894 \pm 0.5174(0.0040)$ & $-0.5655 \pm 1.0231(0.5804)$ \\
& C18:2 & $-0.2418 \pm 0.2810(0.3894)$ & $0.8165 \pm 0.5983(0.1724)$ \\
\end{tabular}

${ }^{1}$ Mean \pm standard error (p-value). 
activities (Zhang et al., 2008). These particular positive effects of CLA feeding under stressful situations were also found in the present work. There is one study (Aydin, 2007) where broiler chicks fed CLA under a stressful situation induced by vaccination showed positive SMD on FBW (Figure 1A). The positive effect of CLA feeding on growth performance under normal conditions can be found in other animals. CLA was reported to act as a fat-to-lean repartitioning in growing pigs and it can consequently result in an improvement in FCR (Dugan et al., 1997; Ostrowska et al., 1999). However, even though CLA can improve growth variables (weight gain and feed conversion ratio), it cannot be effectively positive when its incorporation rate is relatively high (exceeding 1.0\%) (Szymczyk et al., 2001). However, it is not easy to find the result that shows positive effects of CLA feeding on growth performance particularly in broiler chicken. So, it might be concluded that CLA can obviously affect whole body metabolism of broiler chicken, although these do not translate to positive effects on growth performance. Therefore, feeding CLA with the aim of improving growth will not be suitable.

\section{Conjugated linoleic acid and fatty acids in broiler chicken meat}

Many studies have proposed that CLA feeding can reduce fat deposition and increase lean meat content. These modifications might be explained by its activity on lipoprotein lipase to increase lipolysis (Park et al., 1997). Generally, many results for meat fatty acid profiles from broilers fed CLA show increased saturated fatty acids and decreased unsaturated fatty acids. These changes were supposed to be due to the inhibition of $\Delta^{9}$ desaturase activity in liver and consequent impaired conversion of C18:0 to C18:1 (Lee et al., 1998; Suksombat et al., 2007; Szymczyk et al., 2001). Another possible mechanism proposed was that CLA can be used as a substrate for $\Delta^{6}$ desaturase which converts linoleic acid to arachidonic acid resulting in a high content of linoleic acid in broiler chicken meat (Shin et al., 2011). However, in this study, the summary effect of CLA feeding on linoleic acid was negative and contradictory to previous findings. In this study, CLA feeding increased linolenic acid. This increase can be explained by differences in affinity between CLA and linolenic acid to $\Delta^{6}$ desaturase. CLA was reported to have a higher affinity to $\Delta^{6}$ desaturase than linolenic acid (Shin et al., 2011). This implies that dietary CLA is used for a substrate of $\Delta^{6}$ desaturase and subsequently it inhibits conversion of linolenic acid. Moreover, it was suggested that this increment of n-3 PUFA could be achieved by the incorporation of CLA from a particular oil source (e.g. flaxseed oil) (Du and Ahn, 2003). Even though, the effect of CLA feeding on its accumulation in meat was not investigated in the present study, the possibility of elevated
CLA content in the meat of broiler was proposed and the supporting results were reported in a study by Sirri et al. (2003).

\section{CONCLUSION}

This study showed that CLA could modify metabolism and metabolic rate in broiler chicken. However, the matter would be the goal of a CLA feeding strategy because CLA could reduce productivity and increase SFAs concentration in meat. CLA can increase n-3 PUFA content in meat. Therefore, CLA can be applied as an additive to produce meat containing rich n-3 PUFA and low n-6/n-3 ratio. However, the exchange of compensating for decreased growth performance with improved meat quality and customers preference should be considered.

\section{ACKNOWLEDGEMENT}

This work was supported by "Cooperative Research Program for Agriculture Science and Technology Development (Project No. PJ007800)" Rural Development Administration, Korea.

\section{REFERENCES}

Aletor, V. A., K. Eder, K. Becker, B. R. Paulicks, F. X. Roth, and D. A. Roth-Maier. 2003. The effects of conjugated linoleic acids or an alpha-glucosidase inhibitor on tissue lipid concentrations and fatty acid composition of broiler chicks fed a low-protein diet. Poult. Sci. 82:796-804.

An, B. K., K. H. Shinn, Y. Kobayashi, K. Tanaka, and C. W. Kang. 2003. Excessive dietary conjugated linoleic acid affects hepatic lipid content and muscular fatty acid composition in young chicks. Asian-Aust. J. Anim. Sci. 16:1171-1176.

Aydin, R. 2007. Effect of dietary oils and conjugated linoleic acid on the growth performance of broilers vaccinated with the $\mathrm{La}$ Sota Newcastle vaccine. S. Afr. J. Anim. Sci. 37:74-80.

Badinga, L., K. T. Selberg, A. C. Dinges, C. W. Corner, and R. D. Miles. 2003. Dietary conjugated linoleic acid alters hepatic lipid content and fatty acid composition in broiler chickens. Poult. Sci. 82:111-116.

Chin, S. F., W. Liu, J. M. Storkson, Y. L. Ha, and M. W. Pariza. 1992. Dietary sources of conjugated dienoic isomers of linoleic acid, a newly recognized class of anticarcinogens. J. Food Compost. Anal. 5:185-197.

Cleland, L., M. James, and S. Proudman. 2006. Fish oil: what the prescriber needs to know. Arthritis Res. Ther. 8:202-210.

Crespo, N., and E. Esteve-Garcia. 2001. Dietary fatty acid profile modifies abdominal fat deposition in broiler chickens. Poult. Sci. 80:71-78.

Du, M., and D. U. Ahn. 2003. Dietary CLA affects lipid metabolism in broiler chicks. Lipids 38:505-511.

Dugan, M. E. R., J. L. Aalhus, A. L. Schaefer, and J. K. G. Kramer. 1997. The effect of conjugated linoleic acid on fat to lean repartitioning and feed conversion in pigs. Can. J. Anim. Sci. 
77:723-725.

Hur, S. J., G. B. Park, and S. T. Joo. 2007. Biological activities of conjugated linoleic acid (CLA) and effects of CLA on animal products. Livest. Sci. 110:221-229.

Javadi, M., M. J. H. Geelen, H. Everts, R. Hovenier, S. Javadi, H. Kappert, and A. C. Beynen. 2007. Effect of dietary conjugated linoleic acid on body composition and energy balance in broiler chickens. Br. J. Nutr. 98:1152-1158.

Kim, Y. J., B. K. Kim, and Y. B. Yoon. 2008. Effect of dietary conjugated linoleic acid on growth perfomance, carcass charateristics and muscular fatty acid composition in broier. Korean J. Food Sci. 28:451-456.

Ko, Y. H., H. Y. Yang, and I. S. Jang. 2004. Effect of conjugated linoleic acid on intestinal and hepatic antioxidant enzyme activity and lipid peroxidation in broiler chickens. Asian-Aust. J. Anim. Sci. 17:1162-1167.

Ko, Y. H., H. Y. Yang, S. Y. Kang, and I. S. Jang. 2005. Influence of dietary conjugated linoleic acid on growth performance and body fat metabolism in broiler chickens. J. Anim. Sci. Technol. 47:195-204.

Lee, K. N., M. W. Pariza, and J. M. Ntambi. 1998. Conjugated linoleic acid decreases hepatic stearoyl-CoA desaturase mRNA expression. Biochem. Biophys. Res. Commun. 248:817-821.

Lee, K. H., S. Jung, H. J. Kim, I. S. Kim, J. H. Lee, and C. Jo. 2012. Effect of dietary supplementation of the combination of gallic and linoleic acid in thigh meat of broilers. Asian-Aust. J. Anim. Sci. 25:1641-1648.

Ostrowska, E., M. Muralitharan, R. F. Cross, D. E. Bauman, and F. R. Dunshea. 1999. Dietary conjugated linoleic acids increase lean tissue and decrease fat deposition in growing pigs. J. Nutr. 129:2037-2042.

Pariza, M. W., S. H. Ashoor, F. S. Chu, and D. B. Lund. 1979. Effects of temperature and time on mutagen formation in panfried hamburger. Cancer Lett. 7:63-69.

Park, Y., K. Albright, W. Liu, J. Storkson, M. Cook, and M. Pariza. 1997. Effect of conjugated linoleic acid on body composition in mice. Lipids 32:853-858.

Ponte, P. I. P. P., S. P. S. Alves, R. J. B. R. Bessa, L. M. A. L. Ferreira, L. T. L. Gama, J. L. A. J. Brás, C. M. G. A. C. Fontes, and J. A. M. J. Prates. 2008. Influence of pasture intake on the fatty acid composition, and cholesterol, tocopherols, and tocotrienols content in meat from free-range broilers. Poult. Sci. 87:80-88.

R Development Core Team. 2010. R: A language and environment for statistical computing. Vienna, Austria. R Foundation for Statistical Computing. Retrived from http://www.R-project.org
Schmid, A., M. Collomb, R. Sieber, and G. Bee. 2006. Conjugated linoleic acid in meat and meat products: A review. Meat Sci. 73:29-41.

Schreiner, M., H. W. Hulan, E. Razzazi-Fazeli, J. Böhm, and R. G. Moreira. 2005. Effect of different sources of dietary omega-3 fatty acids on general performance and fatty acid profiles of thigh, breast, liver and portal blood of broilers. J. Sci. Food Agric. 85:219-226.

Shin, D., C. Narciso-Gaytán, J. H. Park, S. B. Smith, M. X. Sánchez-Plata, and C. A. Ruiz-Feria. 2011. Dietary combination effects of conjugated linoleic acid and flaxseed or fish oil on the concentration of linoleic and arachidonic acid in poultry meat. Poult. Sci. 90:1340-1347.

Shin, D., G. Kakani, A. Karimi, Y. M. Cho, S. W. Kim, Y. G. Ko, K S. Shim, and J. H. Park. 2011. Influence of dietary conjugated linoleic acid and its combination with flaxseed oil or fish oil on saturated fatty acid and n-3 to n- 6 fatty acid ratio in broiler chicken meat. Asian-Aust. J. Anim. Sci. 24:1249-1255.

Simon, O., K. Männer, K. Schäfer, A. Sagredos, and K. Eder. 2000. Effects of conjugated linoleic acids on protein to fat proportions, fatty acids, and plasma lipids in broilers. Eur. J. Lipid Sci. Technol. 102:402-410.

Simopoulos, A. P. 1999. Essential fatty acids in health and chronic disease. Am. J. Clin. Nutr. 70:560s-569s.

Sirri, F., N. Tallarico, A. Meluzzi, and A. Franchini. 2003. Fatty acid composition and productive traits of broiler fed diets containing conjugated linoleic acid. Poult. Sci. 82:1356-1361.

Suksombat, W., T. Boonmee, and P. Lounglawan. 2007. Effects of various levels of conjugated linoleic acid supplementation on fatty acid content and carcass composition of broilers. Poult. Sci. 86:318-324.

Szymczyk, B., P. M. Pisulewski, W. Szczurek, and P. Hanczakowski. 2001. Effects of conjugated linoleic acid on growth performance, feed conversion efficiency, and subsequent carcass quality in broiler chickens. Br. J. Nutr. $85: 465-473$.

Takahashi, K., K. Kawamata, Y. Akiba, T. Iwata, and M. Kasai. 2002. Influence of dietary conjugated linoleic acid isomers on early inflammatory responses in male broiler chickens. Br. J. Nutr. 43:47-53.

West, D. B., J. P. Delany, P. M. Camet, F. Blohm, A. A. Truett, and J. Scimeca. 1998. Effects of conjugated linoleic acid on body fat and energy metabolism in the mouse. Am. J. Physiol. 275:R667-R672.

Zhang, H. J., Y. M. Guo, Y. D. Tian, and J. M. Yuan. 2008. Dietary conjugated linoleic acid improves antioxidant capacity in broiler chicks. Br. Poult. Sci. 49:213-221. 